\title{
Sorting Out the Standards: What Every Records and Information Professional Should Know
}

\author{
Margaret Pember \\ Department of Media, Society and Culture, Curtin University of Technology, Perth, \\ Western Australia
}

\begin{abstract}
This article provides an overview of standards and the use of standards as an essential tool of records and information management (RIM) practice. The use of standards is widespread, an accepted mechanism to promote a common understanding between individuals and businesses in both private and business activities in all aspects of life. "Standards generally go unnoticed. They are mostly quiet, unseen forces, such as specifications, regulations and protocols, that ensure that things work properly, interactively, and responsibly" (Office of Technology Assessment, Congress, 1992). Standards today are big business with over half a million published worldwide through over 1,000 recognized standards organizations. The use of standards in records management is not something new ushered in by the advent of ISO 15489. They have long been a mechanism used by proficient and professional records managers for determining, establishing and improving records management practice. The key is to make the most of them!
\end{abstract}

\section{Introduction}

Dictionaries provide many meanings for the word standard. Common usage ranges from the value of currency (the gold standard), purity and fineness of metals such as gold and silver (hallmark), to behaviour or beliefs regarded as socially acceptable (norms). Throughout the definitions is the understanding that a standard is something 'taken by general consent as a basis for comparison; an approved model... a grade or level of excellence, achievement or advancement... a level of quality which is regarded as normal, adequate, acceptable, average... serving as a basis of weight, measure, value or comparison, or judgement... ${ }^{1}$

A standard in modern business parlance has a very precise meaning, being "a published document which sets out specifications and procedures designed to ensure that a material, product, method or service is fit for its purpose and consistently performs the way it was intended to" (Standards Australia ${ }^{2}$ ). It is an agreement determined by consensus and prescribes a minimum conformance level or more usually, accepted best practice, for a product, procedure or service.

The National Standards Policy Advisory Committee’s (1978: 6) definition of a standard as “a prescribed set of rules, conditions, or requirements concerning definitions of terms; classification of components; specification of materials, performance, or operations; delineation of procedures; or measurement of quantity and quality in describing materials, products, systems, services, or practices" is still as valid today as it was 30 years ago when first posited. ${ }^{3}$

As noted on the ANSI (American National Standards Institute) site, standards are nothing new, they have probably existed since the beginnings of civilization. As human life became more complex a need was recognized for some commonality to facilitate communication, particularly on issues pertaining to survival such as the gathering or production of food and

\footnotetext{
${ }^{1}$ Macquarie Library. (2001). The Macquarie Dictionary. $3^{\text {rd }}$ edit. This Dictionary actually lists 25 meanings for the term 'standard'.

${ }^{2}$ Standards Australia: definition of standard, etc. http:www.standards.org.au/cat.asp?catid=2\&ContentId=40

${ }^{3}$ This definition is widely quoted in the literature, particularly on webpages.
} 
especially trade. The development of calendars by the Sumerians 5000 years ago is an example of a standard designed to give man a common understanding of the passing of time and the seasons. About the same time standards were developed for weights and measures. Other important examples noted by ANSI include the standardisation of the rail gauge in the $19^{\text {th }}$ century and the early fire safety standards of the $20^{\text {th }}$ century. From such simple beginnings civilisation has developed to the extent that standards are now commonplace and influence many of the actions and interactions of man across the globe ranging from health and safety, to trade and commerce, to building and construction, to technology and even recordkeeping.

\section{Types of standards}

An understanding of the various types of standards is valuable in the determination of their usefulness to a particular RIM program.

There are many ways to categorise standards. ${ }^{4}$ For example they can be divided simply into mandatory, those which must be complied with; and voluntary, where the user has a choice about compliance. Mandatory standards are usually required under specific legislation or regulation and involve auditing, certification and demonstrated conformance, depending upon the particular standard and its use, whereas voluntary standards are often enshrined in a voluntary code of practice. Voluntary standards may become quasi-mandatory when government legislation ${ }^{5}$, policies, principles or standards are based upon them or when government agencies require demonstrated conformance with them from suppliers. This is common in Australia where the newer recordkeeping legislation was based to a large extent firstly on AS 4390 and then ISO/AS 15489. Most Australian states' recordkeeping authorities firmly ground principles and practice on the standards. For example, in Western Australia, the State Records Commission (2002) released a number of principles, policies and standards based on the standard to promote best practice and compliant recordkeeping. ${ }^{6}$ Other voluntary standards, such as ISO 9000, are also considered by many to be essential, although not mandatory, for marketing or other purposes.

Standards can also be broadly sub-divided into the categories of product, process and management system standards. Product standards govern characteristics related to quality and safety and ensure that the product will serve its purpose effectively as stated in the standard. Process standards refer to the conditions under which products and services are to be produced, packaged or refined, that is operational efficiency and quality. Management system standards assist organizations to manage their operations usually through the development of a suitable framework to support the product and process activities (for example ISO 9000 quality and ISO 14000 environmental standards). When used in combination they allow the organization to consistently achieve at best practice levels.

Stephens (2000: 15) highlights the difference between:

de jure or legal standards, those officially issued by governments or standards bodies and de facto standards, those not issued by such bodies but nevertheless considered valid standards because they have been widely adopted by a community of users. De facto standards are synonymous with best practices and often result from the practices of specific vendors who dominate a given market. Thus, whatever technical approaches they adopt to a given aspect of information management become, in effect, de facto standards for the entire industry and user community. Such vendors are in a position to dictate standard practices, regardless of whether any standards-setting body officially endorses them.

\footnotetext{
${ }^{4}$ See NIST http://ts.nist.gov/ts/htdocs/210/ncsci/stdpmr.htm\#Foreword

${ }^{5}$ Note the huge impact of the Sarbanes-Oxley Act in the US.

${ }^{6}$ State Records Commission of Western Australia Principles and Standards available online:

http://www.sro.wa.gov.au/src/policies.html\#principles
} 
Roberts (1998: 1) identifies two broad categories of standards based on function: interoperability and best practice. Interoperability standards "serve as a specification for the attributes of things that are required to work together, or otherwise interact with, other things from other sources..." whereas best practice standards "serve to describe processes, practices and procedures that should be followed to achieve a desired outcome."

Competency standards differ in that they focus on the workplace performance of people. They identify the level of competence required by individuals operating particular machines or carrying out particular tasks in the workplace. ${ }^{7}$ They cover all aspects of workplace performance at all levels. Industry-specific competency standards ${ }^{8}$ set out the skills and knowledge required in individual industry sectors and range from low entry-level skills to high-level management skills. They are usually stated in terms of units of competency to be achieved and recognized through a competency development program or framework. They are useful for mapping the knowledge and skills required by employees in particular industry sectors, recruitment requirements of employers, workplace training and development programs, performance management, career planning, and so forth. They are particularly useful for assessing and recognising the skills acquired by those who have not necessarily had access to formal education programs.

\section{Why standards are used}

Standards provide enormous social and economic benefits in all aspects of human endeavour by enabling interoperability, ensuring quality, safety, consistency, uniformity, reliability, economic efficiency, and so forth, across organisational, state, national and international borders. Breitenberg (1987: 7) maintains that "standards permit society to make more effective use of its resources and allow more effective communication among all parties to particular activities, transactions, or processes.” Whatever the particular standard, it provides a measure to assess conformity with a stated objective or set of objectives. One can rely on the product, service or system consistently performing to an identified level of excellence when it conforms to or is compliant with the relevant standard.

Mackay (2000:4) notes the major benefits of the use of standards as:

simplification through the reduction of product varieties and sizes; interchangeability of products due to size standardization; reduced production costs due to economies of scale; increased reliability of product performance; reduced purchase costs due to increased competition; improved customer confidence and communication between buyers and sellers; increased safety of products; and reduced legal liability.

Mackay goes on to cite the modern computer as an example of the use of standards from the basic standardization of the keyboard to the interconnectivity of the hardware to the use of standardized computer languages and programs.

Such benefits or advantages can be translated into "records speak" to sell the need for standardization in records management. For example, the use of standards limits the waste of staff time and effort by providing a pattern or framework for best practice through standardised action or conformity, thus reducing the re-invention of the wheel syndrome. Even the standardization through procedural documentation of a simple routine activity like the data-entry of corporate names speeds data-entry as staff do not have to make major decisions each and every time, they simply follow the established (and documented!)

\footnotetext{
${ }^{7}$ For examples of competency standards in recordkeeping see the Australian, British and Canadian competency standards. ARMA International is also embarking on a competencies project with an expected completion date of December 2006. See specific references at end of paper.

${ }^{8}$ Industry-specific competency standards have been developed in a whole range of job skill areas in most developed countries, e.g. accountancy competencies include accounting, audit, taxation, company secretarial, corporate finance skills, etc. Other examples of skill areas are human resources, computing, and marketing.
} 
procedure, often called a business protocol). Once a best practice procedure has been developed and formally documented for a particular activity in records management all should follow that procedure until a change in the business activity requires a change in the procedure, which then becomes the standard procedure. Costs are lower if procedures are standardized (increased productivity), training is also simplified when there is only one accepted practice for any specific activity, and the customer group, especially management, is more accepting of procedures based on recognised standards so standards also have an additional role as marketing or PR tools.

\section{Development of standards}

Early standards used in the business context were:

unique documents, part of a single contract between supplier and purchaser. Later, the concept of common Standards evolved, where the same Standard could be used across a range of transactions. This portability, offering a uniform set of criteria, is the basis of modern standardization. It uses common knowledge, common requirements, and common needs to avoid reinventing the wheel (Standards Australia www.standards.com.au).

Standards are usually developed through the work of a group of dedicated expert volunteers in a specific professional area attached to a recognised standards body. The expert teams or technical committees (TCs) established to develop specific standards work on the principles of openness, transparency, balance, fairness and consensus. It is imperative that these teams or technical committees be balanced to avoid undue representation and possible bias from any particular interest group. Once a standard has navigated the rigorous standards process successfully it is published and promulgated for use. Theoretically it will be reflect "best of breed" or "best practice" for the particular product, procedure or service.

Of particular import to recordkeeping is TC 46, ISO's technical committee for information and documentation standards. ${ }^{9}$ TC 46 has various subcommittees such as TC 46/SC 4 which focuses on technical interoperability; TC 46/SC 8 which focuses on quality statistics and performance evaluation; TC 46/SC 9, which focuses on the identification and description of information resources; and TC 46/SC 11 which focuses specifically on archives and records management by providing standards for the "creation and management of documents, records and archives as evidence of transactions and covering all media, including digital, multimedia and paper”.

\section{Role of regulating authorities and professional bodies in standards development}

Consensus among interested parties or stakeholders provides mutually agreed standards for products and services from agriculture to construction to quality to consumer safety. The focus of many standards programs today is the development of standards to promote a safe and sustainable world environment and at the same time economic efficiency and international competitiveness.

The idea that standards be developed through a consensus-based process infers the existence of a decision-making body to oversee and validate the standards process. Like standards themselves such bodies exist worldwide. Standards today are big business with over half a million published worldwide through over 1,000 recognized standards organizations. Of particular import are ISO (International Organization for Standardization) and ANSI (American National Standards Institute). The World Standards Services Network (WSSN) is a network of publicly accessible World Wide Web servers of standards organizations around

\footnotetext{
${ }^{9}$ About ISO Technical Information and Documentation Committee 46 NISO website http://www.niso.org/international/TC46
} 
the world. Through the Web sites of its members, WSSN provides information on international, regional and national standardization and related activities and services.

National and state authorities with responsibility in various areas also develop and/or endorse standards for application in their particular jurisdictions. Professional bodies such as ARMA International also play a significant role in the development of standards. ARMA has been an accredited standards development organization with the American National Standards Institute (ANSI) since 1986. ARMA's Standards Development Committee (SDC) develops guidelines, technical reports, and standards to address relevant issues in records and information management (RIM). In addition, ARMA participates in the standards development process of other organizations when a RIM perspective is relevant. For example, ARMA is represented on applicable ISO standards development committees such as TC 46/SC11 Archives/Records Management (ARMA, 2005a, b).

\section{The cost of standardization}

No one denies that the implementation of standardization involves a considerable outlay of resources at the time, but subsequent savings result in terms of time saved by following a consistent and approved method for a particular process. One must balance the overall implementation costs incurred against the cost of non-implementation. A product or service that conforms to an established and recognised standard should be 'best of breed' providing a competitive edge over a similar product or service that does not conform to a recognized standard. The market appeal is considerably enhanced when prospective clients can have a certain level of confidence that the product or service will consistently meet certain identified criteria. Similarly records management programs can benefit with improved services to the client group, demonstrated cost savings through the reduction of time wasted and increased productivity, increased visibility and marketability to management, higher user acceptance and confidence with conformance to records management standards. Not only is the records management program enhanced operationally, information risk exposure is greatly reduced. Many organisations in the past few years have discovered to their detriment that lack of standards in recordkeeping practice can prove very costly indeed. Adherence to standards is not a luxury in today's litigious corporate environment; it should be the norm. ${ }^{10}$

Major costs in the implementation of standards for records management revolve around staff time. One has to release current staff from all or some portion of their current duties or employ additional staff, often on a contract or consultancy basis, to identify, adapt or develop the required standards as necessary, and formally document through policies and procedures. And it doesn't stop here; staff must be trained in their application. And of course all standards should be subject to a regular review process to assess their continuing relevance.

Costs involved for businesses conforming to standards is greater when standards have to be audited as the cost of the independent third party audit and certification process is additional to the initial development and implementation costs of conformance. However, certification by a competent independent third party confers greater credibility on the product, process or service and for many is absolutely essential for marketing purposes even if not mandatory.

\section{Use of standards in RIM}

The use of standards in recordkeeping creates a professional environment of best practice. They establish a common language and understanding among recordkeeping practitioners to enable individuals and organizations to create systems, policies and procedures that ensure high operational quality recordkeeping and at the same time minimize corporate information risk exposure thus leading to exceptional records and information management performance.

${ }^{10}$ The French use the terms norme and normalisation for standard and standardization. 
As well as providing a best practice framework for the establishment and maintenance of recordkeeping programs, standards have a monitoring and audit role. They provide a reference point for measurement, for example, ISO 15489 provides a global RIM best practice benchmark against which to evaluate any recordkeeping program and a committee (Standards Australia IT/21/5 subcommittee, chaired by Judith Ellis) is currently working on a standard to assist Australian organisations assess their level of compliance with ISO 15489. It is expected that a draft will be released for comment soon.

Professional record and information managers have long been interested in developing and using standards to ensure efficiency, effectiveness, and accountability, reduce costs, and mitigate risk in the management of corporate records and information. In the past these standards may well have been developed largely in-house by the records manager and enunciated in the recordkeeping policies and procedures of the organization. Such initiatives covered all aspects of recordkeeping from classification to retention and disposal. This level of standard development was common in well-managed recordkeeping programs long before the advent of national and international standards for recordkeeping.

Many regulating authorities ${ }^{11}$ also became involved in the development and distribution of standards for their specific jurisdictions (see next page) but the move today is towards standards developed by mutual consensus and recognised and applied across the profession, both nationally and internationally such as AS 4390 and ISO 15489. Other examples of standards initiatives at the national and international level relative to records management include those applying to controlled vocabulary ${ }^{12}$, metadata ${ }^{13}$, document imaging ${ }^{14}$, electronic recordkeeping ${ }^{15}$, information security ${ }^{16}$, risk mitigation ${ }^{17}$, and so forth (this list is not exhaustive).

One of the first standards to have an international impact on recordkeeping was ISO 9000. This suite of quality standards specifies particular requirements for the management of quality records, such as the ability to identify, collect, index, store and access the records, while at the same time preventing loss or damage and ensuring retention in accordance with a relevant schedule. Companies wishing to obtain ISO 9000 certification must be able to demonstrate good recordkeeping systems, including regular audit by external independent bodies (Taylor, 2003). In the early days of ISO 9000 certification many companies failed the audit because of sub-standard recordkeeping systems (Brumm, 1995).

An early Australian standard AS 2828, first published in 1985, outlined standards for hospital medical records. This particular standard was very specific about the requirements for the physical aspects of hospital medical records, such as size, quality, layout, colour, order of filing, record cover and method of fitting the medical record within the record cover. This was superseded in 1999 with a best practice standard for the management of paper-based health care records, and covers similar issues as the earlier standard (Standards Australia, 1985, 1999).

\footnotetext{
${ }^{11}$ For example, the State Records Office of Western Australia has been publishing standards for use by state and local government authorities for over 20 years.

$\underline{12}$ For example ISO 5964-1985; ISO5963-1985; ISO 2788-1986.

${ }^{13}$ For example ISO /TS 23081-1:2004.

${ }^{14}$ For example ISO 10196-2003.

${ }^{15}$ There is a lot of research in the area of electronic recordkeeping: e.g. UBC-MAS Project, VERS Project, InterPARES, etc. and various standards/technical reports are already available, e.g. ANSI/AIIM/ARMA TR482004. This TR defines, describes, and differentiates between electronic document management systems (EDMS) and electronic records management systems (ERMS) and provides a framework for their integration. See also DoD 5015.2-STD and MoReq.

${ }^{16}$ For example ISO/IEC 17799.

${ }^{17}$ For example AS/NZS 4360-1999; ISO/IEC 16085-2004.
} 
Australia's AS 4390 Records Management, published in 1996, was the first generalised national standard for records management and this standard was used as the basis for the development of the first international records management standard published in 2001. This standard (ISO 15489) is recognized worldwide as establishing the baseline for excellence in records management programs, regardless of the size, type or location of the organization, and regardless of records format or content. As Connelly (2001) points out, the standard provides a blueprint for the establishment, structure, monitoring and auditing of a best practice records management program. It allows an organization to efficiently and effectively record and retrieve information, thus enhancing decision-making, productivity, and accountability, and at the same time reduce information risk exposure. Stephens (2000: 69) believes it "is hard to overstate the new standard's significance. It has the potential to add a stamp of global legitimacy to records management as a business practice and elevate it to a new level". The standard was developed by a truly international committee (ISO TC46/SC11) consisting of delegates from Australia, Canada, China, Denmark, France, Germany, Ireland, Japan, Poland, Russia, Sweden, the Ukraine, the United Kingdom, and the United States of America. For an interesting account of the development of the standard see Mike Steemson's paper presented at the Joint National Conference of the Australian Society of Archivists and the Records Management Association of Australasia in Hobart in 2001 (Steemson, 2001/2).

Another standard having application to records management programs is the Australian standard, Work process analysis for recordkeeping (AS 5090-2003). This standard has been developed to provide guidance for organizations undertaking work process analysis for recordkeeping purposes in support of AS ISO 15489.

\begin{abstract}
All organizations create records from their business or work processes. To identify what records need to be created for those work processes, and to manage those records, the work processes themselves need to be analysed from a recordkeeping viewpoint. This Standard provides guidance on undertaking work process analysis for recordkeeping purposes.

In addition, as more of their business activities operate in an electronic environment, organizations have the opportunity to integrate recordkeeping processes with the work processes themselves. Processing orders, accounts, payments or wages, stock control, managing assets, managing quality assurance systems and contract management are examples of business activities in which recordkeeping is normally integrated with the processing of transactions. As computer applications become more sophisticated, there exists the possibility of automating work processes, including the recordkeeping processes, to less structured activities such as complaint management and general correspondence management. Work process analysis from a recordkeeping perspective is essential for developing such an automated application (Preface).
\end{abstract}

As noted specific guidance standards also exist for the management of the recordkeeping program in particular jurisdictions. These are usually developed by those with a particular responsibility or authority in the area. For example, the State Records Commission of Western Australia has issued a number of principles and standards relevant to Western Australia (http://www.sro.wa.gov.au/src/policies.html\#principles). An example from the Public Record Office of Victoria is the VERS (Victorian Electronic Records Strategy) Standard for the Management of Electronic Records, first issued in 1999 and revised in $2003^{18}$. The DIRKS (Designing and Implementing Recordkeeping Systems) ${ }^{19}$ methodology from National Archives of Australia and State Records New South Wales provides guidance based on the international standard, primarily for Australian government agency records and information management project teams and consultants. The National Archives of Australia

\footnotetext{
${ }^{18}$ http://www.prov.vic.gov.au/vers/standard

${ }_{19}$ http://www.naa.gov.au/recordkeeping/dirks/dirksman/dirks.html
} 
(NAA) also promote standards through the e-permanence ${ }^{20}$ initiative which provides a whole suite of products and services based on best practice standards and legislative requirements.

Similarly The National Archives (TNA) in the United Kingdom, the National Archives and Records Administration (NARA) ${ }^{21}$ in the United States, and other recordkeeping authorities/regulators in the international recordkeeping sphere develop standards and guidance for archive and records management professionals operating in their particular jurisdictions. National records authorities also identify and promote the use of appropriate standards developed by others, or in concert with others. For example, NARA, after thorough review, endorsed the Department of Defense Electronic Records Management Software Application Design Criteria Standard (DoD 5015.2-STD), for use by all federal agencies. NARA “evaluated the DoD standard for recordkeeping functionality and has determined that DoD-certified products comply with the relevant provisions of the Federal Records Act and NARA regulations with respect to the creation, maintenance and use, and disposition of Federal records" (NARA, 2003). The TNA's Framework of Standards ${ }^{22}$, developed after an extensive consultation process, provides a "range of standards and guidelines in all aspects of record keeping". The TNA notes that these standards "offer comprehensive pointers to best practice in every field relevant to the operation of publicly and privately funded repositories". The Framework (2004) provides comprehensive lists of standards and best practice guidelines on issues ranging from records storage, cataloguing/indexing, and electronic records, to conservation and preservation. Work on the Framework is ongoing.

The competency standards for archives and records in Australia were developed as a major national project and most recordkeeping qualifications courses in Australia were mapped to these competencies, but when the competencies were downgraded from university level the competency standards lost much of their initial impact and value, as they were no longer appropriate for the assessment of university-level courses in recordkeeping. Picot (2001) gives a detailed account of the development of the archives and records competency standards in Australia. The Australian Archives and Records Educators Forum (ARES) agreed in June 2003 to work together as a joint committee to develop a statement of the core skills and knowledge required by recordkeeping practitioners (Taylor, 2005). The draft statement issued in 2004 by the Joint Education Steering Committee defining this professional knowledge is available for comment on the Records Management Association of Australasia (RMAA) website.

The National Archives (as the Public Record Office) in the UK also developed comprehensive standards for those working in records management. In 1999 the Records Management: Human Resources document was published, providing "three distinctive but inter-related elements” - a competence framework for records practitioners, recordkeeping job and person specifications, and information on staff training and development in records management. In the same year, the Canadian Competency Profile: Information Resources Management Specialists in Archives, Libraries and Records Management (see Alliance of Libraries, Archives and Records Management (ALARM) reference) was issued and tool kits were subsequently developed to enable individuals or organisations to analyse and evaluate skills required by those working in the profession. And of course the CRM program and dedicated university level courses in recordkeeping should also demonstrate practitioner competence in the field.

\footnotetext{
${ }^{20}$ National Archives of Australia http://www.naa.gov.au

${ }^{21}$ National Archives and Records Administration www.archives.gov

22 The National Archives www.nationalarchives.gov.uk/archives/framework
} 


\section{Conclusion}

The range of standards available to the RIM profession offers a comprehensive toolkit for any practitioner or organization endeavouring to establish, maintain, monitor and evaluate a high quality recordkeeping program or the knowledge and skills required by competent recordkeeping practitioners. Those already available to practitioners are evaluated as part of the ongoing standards process and updated as necessary. Many more standards are currently being developed where a need has been identified by the profession.

The consistent use of appropriate standards is an absolute imperative to ensure best practice recordkeeping in an environment of constantly changing management styles, shrinking resources, rapidly evolving technology, increasing demands for legislative compliance, accountability and transparency, and greater needs for interoperability, etc. Only by adherence to best practice standards can the RIM professional create an environment where the recordkeeping requirements of all aspects of the business can be identified, considered and met effectively.

In the past standards have in most cases been offered as voluntary codes of practice for professionals wishing to improve recordkeeping practice. Compliance has not been mandatory and audits have been the exception rather than the norm. Although this is changing in some areas perhaps it is time for those serious about raising the standard of records management practice to become more active. Business scandals across the government and private sectors worldwide indicate that recordkeeping in many instances has been less than adequate. Records and information management programs based on a broad framework of best practice standards can certainly raise the quality of RIM practice and the outcomes contribute to increased business success.

\section{References}

Alliance of Libraries, Archives and Records Management (ALARM). In partnership with the Cultural Human Resources Council. "Competency Profile: Information Resources Management Specialists in Archives, Libraries and Records Management.” Canada: ALARM. 1999. www.fis.utoronto.ca/alarm Tool kits are available from Cultural Human Resources Development Council/Human Resources Development Canada. Retrieved 12 June 2005. http://www.culturalhrc.ca/competencies/irmsProfile/Comp_IRMS_e.pdf

Allman, T.Y. "Fostering a Compliance Culture: The Role of the Sedona Guidelines.” Information Management Journal, 39, 2005 (2): pp. 54-59.

American National Standards Institute (ANSI). “Through History With Standards.” Retrieved 29 May 2005. http://www.ansi.org/consumer_affairs/history_standards.aspx?menuid=5

ANSI/AIIM/ARMA. "TR48-2004: Framework for integration of electronic document management systems and electronic records management systems.” ANSI/AIIM/ARMA. 2004.

ARMA International. (2005). RIM Competency Project. Project updates on the ARMA website http://www.arma.org/news/index.cfm?NewsID=373

ARMA International Standards Development Committee Program. Retrieved 29 May 2005. http://www.arma.org/standards/index.cfm

Australian Archives and Records Educators Forum (ARES). Joint Education Steering Committee. "Draft Statement on the Professional Knowledge Required by Recordkeepers." 2004. Retrieved 22 May 2005.

http://rmaa.com.au/docs/branches/nat/pub/forcomment/DraftProfessional\%20KnowledgeRe quired.pdf 
Breitenberg, MA. “The ABCs of Standards Related Activities in the United States.” (NBSIR 87-3576). Gaithersburg, MD: National Institute of Standards and Technology. 1987.

Retrieved 5 June 2005. http://ts.nist.gov/ts/htdocs/210/ncsci/stdpmr.htm

Brumm, E.K. “ISO 9000 and Records Management.” ARMA Pan Pacific Conference Proceedings. Auckland, NZ: ARMA International. 1995. Printed from CD n.p.

Bryden, A. "Why Standards Matter.” British Journal of Administrative Management, January/February 2004: pp. 28-29.

Connelly, J.C. “The New International Records Management Standard: Its Content and How It Can Be Used.” Information Management Journal, 35(3), 2001: pp. 25-28.

Crockett, M., \& Foster, J. “Using ISO 15489 as An Audit Tool.” Information Management Journal, 38(4), 2004: pp. 46-53.

Department of Defense (US). "Design Criteria Standard for Electronic Records Management Software Applications.” (DoD 5015.2-STD). 1997. Retrieved 12 May 2005. http://www.dtic.mil/whs/directives/corres/html/50152std.htm

Duff, W., \& McKemmish, S. "Metadata and ISO 9000 Compliance.” Information Management Journal, 34, 2000: 4 pages. Retrieved Infotrac 18 July 2005.

European Commission (Interchange of Data between Administrations Programme), \& Cornwall Management Consultants. "Model Requirements for the Management of Electronic Records (MoReq).” 2001. Widely available on the web.

Fisher, P. "Electronic Records As Evidence: The Case for Canada's New Standard.” Information Management Journal, 38(2), 2004: pp. 39-45.

Gable, J. “Everything You Wanted to Know About DoD 5015.2: The Standard Is Not a Panacea or a Guarantee, But it is a Tangible Contribution In a Field Hungry For Guidance.” Information Management Journal, 36(6), 2002: pp. 32-38.

International Organization for Standardization. "ISO 5963-1985: Documentation: Methods for Examining Documents, Determining Their Subjects, and Selecting Indexing Terms.” Geneva: ISO.

International Organization for Standardization. "ISO 5964-1985: Documentation: Guidelines for the Establishment Development of Multilingual Thesauri. Geneva: ISO.

International Organization for Standardization. "ISO 2788-1986: Documentation: Guidelines for the Establishment and Development of Monolingual Thesauri.” Geneva: ISO.

International Organization for Standardization. "ISO 999-1996: Information and Documentation - Guidelines for the Content, Organization and Presentation of Indexes.” Geneva: ISO.

International Organization for Standardization. "ISO 15489-1-2001, Information and documentation - Records management — Part 1: General; and ISO 15489-2 - 2001, Information and documentation — Records management — Part 2: Guidelines.” Geneva: ISO.

International Organization for Standardization. "ISO 10196-2003 Document Imaging Applications: Recommendations for the Creation of Original Documents.” Geneva: ISO.

International Organization for Standardization. "ISO/TR 15801-2004: Electronic Imaging: Information Stored Electronically: Recommendations for Trustworthiness and Reliability." Geneva: ISO. 
International Organization for Standardization. "ISO /TS 23081-1-2004: Information and Documentation - Records Management Processes - Metadata for Records - Part 1:

Principles.” Geneva: ISO.

International Organization for Standardization. "ISO/IEC 16085-2004: Information technology -- Software life cycle processes -- Risk management.” Geneva: ISO.

International Organization for Standardization (ISO). Retrieved 29 May 2005. http://www.wssn.net/WSSN/index.html

Jones, V.A. “Protecting Records: What the Standards Tell Us.” Information Management Journal, 37(2), 2003: pp. 70-74.

Mckay, D.R. “A Tripartite Program For The Expansion of World Trade.” Fred Butcher Memorial Competition: Is there a role for international standardization in the 21st century? British Standards Society. Standards Metadata Library: 2000. Retrieved 5 June 2005. http://www.consortiuminfo.org/metalibrary/detail.php?EID=221\&PID=2

McLean, B. “The ISO 15489 Imperative: Even Organizations Without RIM Problems Can Benefit From An ISO-Driven Records Management 'Health Check'.” Information Management Journal, 36(6) 2002: pp. 25-32.

National Archives, The (UK). Standards page. Retrieved 17 June 2005. http://www.nationalarchives.gov.uk/recordsmanagement/advice/standards.htm

National Archives, The (UK). "Records Management: Human Resources.” Kew, UK: PRO. 1999. Still available on the TNA website. Retrieved 20 June 2005.

http://www.nationalarchives.gov.uk/recordsmanagement/advice/pdf/best_human_resources. pdf

National Archives and Records Administration (NARA). "NARA Bulletin 2003-03.

Endorsement of DoD Electronic Records Management Application (RMA) Design Criteria Standard, version 2.” College Park, MD: NARA.

National Standards Policy Advisory Committee. "National Policy on Standards for the United States and a Recommended Implementation Plan.” National Standards Policy Advisory Committee, Washington, DC: NSPAC. 1978.

National Archives of Australia website. Retrieved 17 June 2005. http://www.naa.gov.au

Office of Technology Assessment (Congress of the United States). "Global Standards: Building Blocks for the Future.” Washington, DC: OTA. 1992. Retrieved 17 June 2005. http://www.wws.princeton.edu/ ota/ns20/year_f.html

Picot, A. "The Story of the Australian Recordkeeping Competency Standards.” Records Management Journal, 11(3), 2001: pp. 143-153.

Records Management Association of Australasia website. http://rmaa.com.au

Roberts, D. "Developing Australian Standards for Records Management.” Sydney, NSW: State Records NSW. 1998. Retrieved 14 May 2005. http://www.records.nsw.gov.au

Standards Australia International website. Retrieved 3 June 2005. http://www.standards.com.au

Standards Australia International. "Hospital Medical Records: AS 2828-1985.” Sydney, NSW: SA. 
Standards Australia International. "Records Management: AS 4390-1996.” Sydney, NSW: SA.

Standards Australia International. "Paper-based Health Care Records: AS 2828-1999.” Sydney, NSW: SA.

Standards Australia International. “Risk Management: AS/NZS 4360_1999.” Sydney, NSW: SA.

Standards Australia International. "Work Process Analysis for Recordkeeping: AS 5090_ 2003.” Sydney, NSW: SA.

Steemson, M. “ISO 15489 set it to music: You're gonna need it!” Informaa Quarterly, 18(1), 2002: pp. 21-28. Paper presented at the Joint Convention of the ASA and RMAA, Hobart, 2001. Also available online: http://www.caldeson.com/hobart01.html

Stephens, D.O, “International Standards and Best Practices in RIM.” Information Management Journal, 34(2), 2000: pp. 68-71.

Stephens, D.O, “The World's First International Records Management Standard.” Records Management Quarterly, 35(3), 2001. Retrieved Infotrac 10 June 2005.

Stephens, D.O., \& Roberts, D. “From Australia: The World’s First National Records Management Standard. 1996 Records Management Quarterly, 30(4), 1996: pp. 3-7, 62.

Taylor, P. “Professional Knowledge of Recordkeepers Defined.” Informaa Quarterly, 21(1), 2005: p. 52.

Taylor, S. “Benchmarking For Records Management Excellence.” Municipal World. 2003. Retrieved 6 June 2005. http://condar.ca/CONDAR\%20Articles/article\%2015\%20RM\%20Benchmarking.pdf

Techstreet. “The What, Why, and How of Standards.” 2005. Retrieved 12 June 2005. http://www.techstreet.com/whystandards.tmpl

State Records Commission (Western Australia). "Principles and Standards.” Perth, WA: SRC, Government of Western Australia. Originally published in the Western Australian Government Gazette, March 2002. Retrieved 6 June 2005. http://www.sro.wa.gov.au/src/policies.html

Weise, C.E., \& Stamoolis, P.G. "ISO 9000: An Opportunity for Records Management Professionals.” Records Management Quarterly, 27(4), 1993: pp. 3-8, 10-11.

World Standards Services Network (WSSN). 2003. Retrieved 30 May 2005. http://www.wssn.net/WSSN/index.html

Author

Margaret Pember is a lecturer in records management and archives at Curtin University of Technology in Perth, Western Australia. She comes from a background in secondary teaching, and records and archives management. She has long been involved at the committee level in both records and archives professional bodies and currently serves on the ARMA International Standards Development Committee (SDC).

Margaret Pember, Information Studies, Department of Media, Society and Culture, Curtin University of Technology, Perth, Western Australia.

Tel: +61 89266 2732; fax: +61 892663166

Email: m.pember@curtin.edu.au http://smi.curtin.edu.au/infostudies/index.cfm 